\title{
OSCILLATION CRITERIA FOR EVEN ORDER NONLINEAR NEUTRAL DIFFERENCE EQUATIONS
}

\author{
D. Seghar, S. Selvarangam And E. Thandapani
}

Abstract. Some new oscillation results are obtained for the even order nonlinear neutral difference equation of the form

$$
\Delta\left(a_{n} \Delta^{m-1} z_{n}\right)+q_{n} f\left(x_{n-\sigma}\right)=0
$$

where $z_{n}=x_{n}+p_{n} x_{\tau(n)}$. Our results generalize and improve some of the existing results. Two examples are provided to illustrate the main results.

Mathematics subject classification (2010): 39A10.

Keywords and phrases: oscillation, even-order, nonlinear, neutral difference equation.

\section{REFERENCES}

[1] R. P. Agarwal,Difference Equations and Inequalities, Marcel Dekker, New York, 2000.

[2] R. P. Agarwal, M. Bohner, S. R. Grace and D. O'Regan, Discrete Oscillation Theory, Hindawi Publ.Co., New York, 2005.

[3] R. P. Agarwal, E. Thandapani And P. J. Y. Wong, Oscillations of higher order netural difference equations, Appl. Math. Lett., 10 (1997), 71-78.

[4] Y. BOLAT AND O. AKIN,Oscillatory behavior of a higher-order nonlinear neutral type functional difference equations with oscillating coefficients, Appl. Math. Lett., 17 (2004), 1073-1078.

[5] Y. BOLAT, O. AKIN AND H. YILDIRIM, Oscillation criteria for certain even order neutral difference equation with an oscillating coefficient, Appl. Math. Lett., 22 (2009), 590-594.

[6] I. GyÖRI AND G. LADAS, Oscillation Theory of Delay differential Equations with Applications, Clarendan Press, Oxford, 1991.

[7] I. KIR AND Y. BOLAT, Oscillation criteria for higher-order neutral delay difference equations with oscillating coefficients, Int. J. Difference Equ., 2 (2006), 219-223.

[8] N. PARHI AND A. K. TRIPATHY, Oscillation of a class of nonlinear neutral difference equations of higher order, J. Math. Anal. Appl., 284 (2003), 756-774.

[9] RUBA Ali-HAmouri AND Ali Zein, Oscillation criteria for certain even order neutral delay differential equations, Inter.J.Diffential Equ., 2014, Article ID 437278, 5 pages.

[10] P. Sundaram, Oscillation criteria for even order neutral difference equations, Bull. Cal. Math. Soc., 92 (2000), 81-86.

[11] M. K. YILDIZ AND O. OCALAN, Oscillation results for higher order nonlinear netural delay difference equations, Appl. Math. Lett., 20 (2007), 243-247.

[12] M. K. YILDIZ AND O. OCALAN, Forced oscillation of higher order nonlinear netuaral difference equations with positive and negative coefficients, Adv. Diff. Eqn., 2012, Article No. 110.

[13] A. ZAFER, Oscillatory and asymptotic behavior of higher order difference equations, Math. Comput. Model., 21 (1995), 43-50.

[14] A. ZAFer And R. S. DAhiYA, Oscillation of a neutral difference equation, Appl. Math. Lett., 6 (1993), 71-74. 